\title{
Versatility of Vein Grafts in Hand Neurovascular Reconstruction - Clinical Cases and Literature Review
}

\author{
Alexandru STOIAN ${ }^{1,3}$, Florin-Vlad HODEA ${ }^{7}$, Roxana-Maria TOMEK ENESCU ${ }^{3}$, \\ Andreea GROSU-BULARDA ${ }^{7}$, Mihaela Cristina ANDREI ${ }^{1}$, Flavia Francesca LITA', \\ Marius POPESCU ${ }^{1}$, Ioan LASCAR ${ }^{1,2}$, Razvan TEODOREANU ${ }^{1,2}$
}

\begin{abstract}
Injuries to the upper limb may determine unexpected simple or complex soft tissue defects, due to different types of underlying injury mechanism, clean cut/stabs, crushing, torsion, avulsion or mixed types, which pose a challenge for the reconstructive surgeon. Ideally, all arterial, venous and nervous lesions, in the distal upper limb should be repaired in an end-to-end technique, outside of injury zones, with healthy ends, in a tension free manner. However, situations arise where, either a tension-free repair is not possible, or a considerable defect is met, often representing a challenge to the surgeon. Therefore, a timely decision is imposed in order to find the most favorable approach to restore limb or segment perfusion, ensuring efficient venous return, as well as providing a sensate repair.

Usage of vein grafts represents an essential tool comprised in the reconstructive surgeon's armamentarium, with high versatility in nerve, arterial and venous reconstruction. Not only does it provide an ideal solution, with high adaptability to each case, but it also may enhance short- and long-term outcome, offering an optimal reconstructive option in any upper limb trauma situation, regardless of etiology.

We aim to describe our therapeutic strategies in a series of challenging trauma cases involving digital structures from the upper limb. Interposed vein grafts were used to re-stablish sensate function in a patient with a collateral digital nerve defect, but also to bridge vital digit arterial defect in a torsion-avulsion thumb amputation, as well as re-establishing venous flow in patients with Urbaniak II finger degloving injury.
\end{abstract}

Keywords: vein graft, upper limb trauma, microsurgery, neurovascular reconstruction, ring avulsion injuries.

'Clinic of Plastic Surgery, Aesthetic and Reconstructive Microsurgery, Emergency Clinical Hospital, Bucharest, Romania ${ }^{2}$ "Carol Davila" University of Medicine and Pharmacy, Bucharest, Romania

${ }^{3}$ Calarasi County Hospital, Romania

\section{Corresponding author.}

Florin-Vlad HODEA, Emergency Clinical Hospital, 8 Floreasca

Avenue, Bucharest, Romania.

E-mail: hodea_florin@yahoo.ro 


\section{INTRODUCTION}

Three decades years ago, Brunelli was the first who attempted to fill a nerve gap using muscle within vein graft $^{1}$. Before his innovative surgery ideas, first attempts of successful interposition vein grafts used to bridge arterial defects were made in the Korean war, however in cases where large vessels were injured, such as the axillary, brachial, iliac, femoral arteries ${ }^{2}$. In current times, bridging defects can be done with either synthetic or autologous grafts ${ }^{3,4}$.

Among the most injured structures, which can question the viability of the traumatized segments, are vessels and nerves. Injury types have different mechanisms in upper limb trauma, such as clean cut, stabs, crushing, torsion, avulsion or mixed types. Extensive tissular destruction by various trauma mechanisms (torsion, avulsion, crush, degloving, mixed) pose a surgical challenge due to structural resulting defects of anatomical functional elements, as a consequence of aggressive debridement until healthy tissues are met. Various methods were described to bridge neurovascular gaps in upper limb trauma 5 .

Present literature is in favor of using an autologous graft, such as a primarily interposed vein graft, in either arterial or vein lesion, rather thanattempting a direct tensioned vascular coaptation of two traumatized vascular stumps, due to the high thrombogenic risk. In addition, nerve bridging using interposed vein graft is indicated in defects between $5 \mathrm{~mm}$ and $3 \mathrm{~cm}^{3,6}$.

\section{MATERIAL AND METHOD}

This paper represents a case series presentation of interposition vein graft used to bridge defects in four patients with nervous, arterial, or venous gaps in the digits: one digital nerve defect, one sub-total amputation of the thumb and two Urbaniak II degloving injuries. The patients were admitted to Clinical Emergency Hospital Bucharest and Calarasi County Hospital in 2021. Full consent was obtained from all the patients in this paper. Data were gathered from the patients' admission charts, hospital paper archives and Hipocrate digital archives. Moreover, we discuss the cases compared to existing literature, drawn from PubMed database, regarding the utility of using such grafts.

\section{CLINICAL CASES PRESENTATIONS}

\section{Case 1}

The first patient is a 36-year-old female who suffered a sub-total amputation of the left index at the level of the proximal interphalangeal joint (PIP), with intact ulnar neurovascular collateral pedicle andintact skin bridge on the ulnar side of the finger. PIP joint arthrodesis was performed using a Kirschner wire, followed by reconstruction of the nerve gap on the functional radial side of the index by using a muscle within vein graft as a nerve conduit with a length of $15 \mathrm{~mm}$.

During follow up, the patient returned with excellent results, presenting a two-point discrimination test comparable to the healthy, contralateral side.

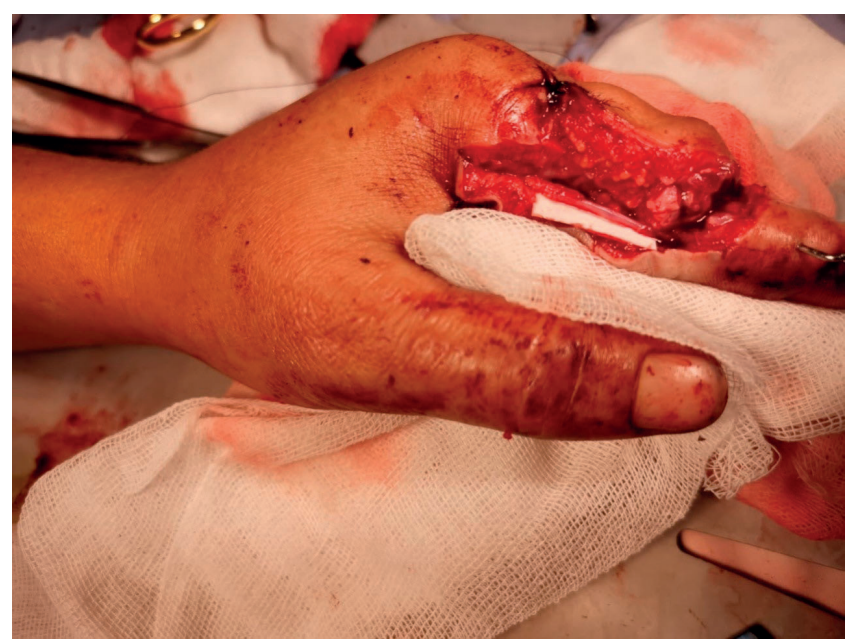

Figure 1. 36-year-old-female with sub-total amputation of left index, with muscle in vein autologous graft

\section{Case 2}

The second case is represented by a 34-year-old female, who suffered a mixed type injury of torsion-avulsion sub-total amputation with a rope of the left thumb, with preservation only of a narrow dorsal skin bridge of $1 \mathrm{~cm}$ and extensor apparatus. A vein graft was harvested from the volar side of the wrist, where an incision was performed to find the flexor pollicis longus. The collateral digital artery on the ulnar side of the thumb was reconstructed with the interposed vein graft, however with a 2:1 mismatch vein to distal artery stump, tailored surgically with wedge resection technique. The particular aspect, encountered in this patient, was a mild malformation of the thumb, known by the patient, but not investigated, with a slightly hypoplastic 
thumb with reduced range of flexion movements in the interphalangeal joint. Intraoperative findings as seen in Figure 3 reveal the abnormal insertion of the flexor pollicis longus at a proximal level, at the base of the thumb.
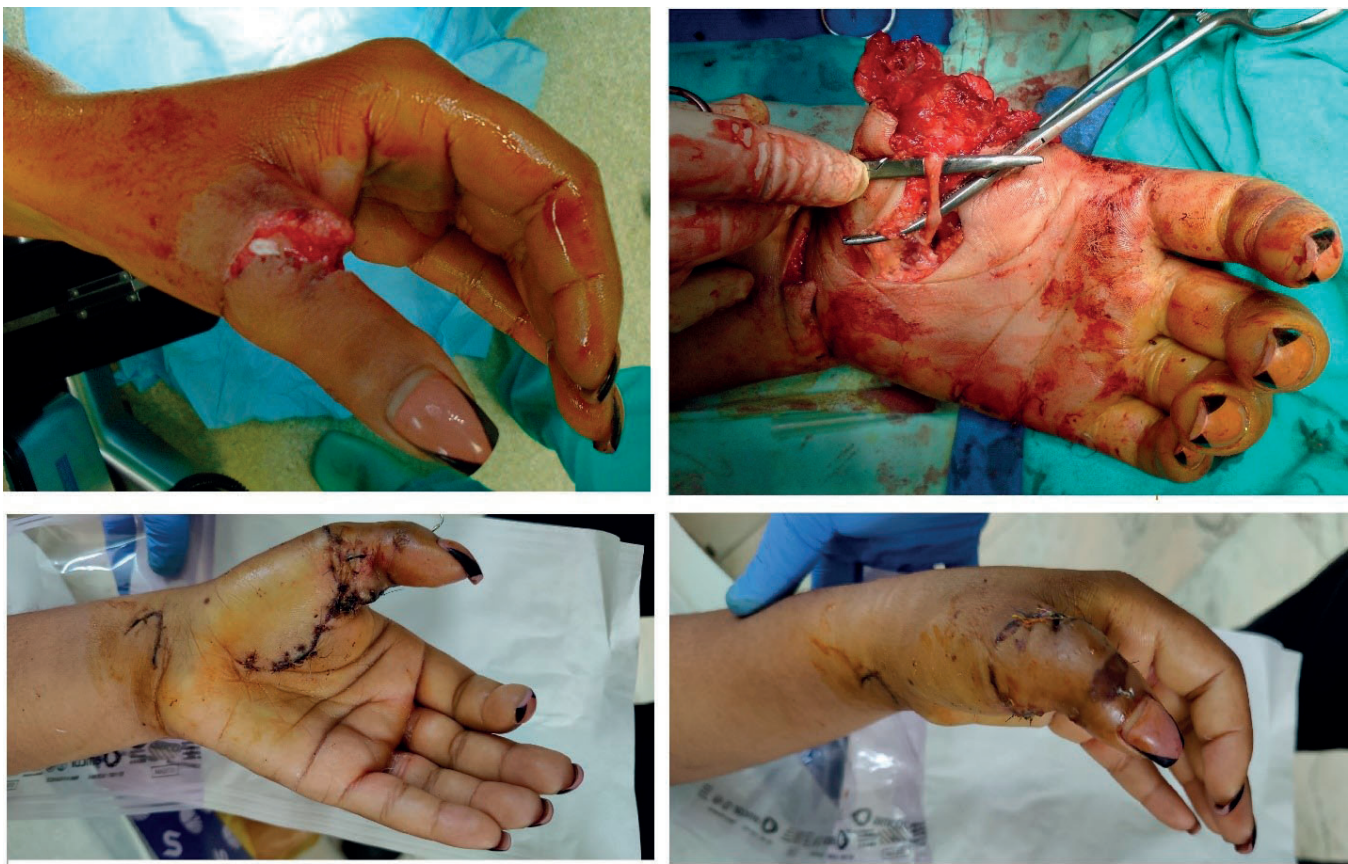

Figure 2. 34-year-old-female with sub-total amputation of the thumb with $1 \mathrm{~cm}$ dorsal skin bridge, as seen in the upper row. In the lower row, an immediate post-operative aspect of the thumb can be seen, with good capillary refill, with no congestion

\section{Case 3}

The third case is a 42-year-old male patient, without any comorbidities, non-smoker, who suffered a ring avulsion injury of the fourth finger of the left hand. The distal interphalangeal joint (DIP) presented unstable dislocation, with extensor tendon lesion over the middle phalanx (zone II). Skin was sectioned circumferentially, but with intact neurovascular pedicle on the ulnar side. The post-operative management of the patient was uneventful, with no signs of venous congestion or skin necrosis.
Post-operatively, the finger presented no complications, with no signs of ischemia, with good evolution, the patient being discharged and integrated in a rehabilitation program. 


\section{Case 4}

The fourth case is a 26-year-old patient, known to be an active smoker, who suffered also a ring avulsion injury, similar to the third case, at the level of the fourth digit of the left hand. This patient presented circumferential skin section at the level of the proximal phalanx, with venous congestion, with one intact neurovascular pedicle, however with crushed and avulsed skin.

Postoperatively, the patient presented good distal perfusion and venous return, however the skin covering the middle phalanx that suffered a crushing injury still maintained impeded vascularization and venous return. On day 4, the patient developed serous phlyctens both on the dorsal and volar side of the middle phalanx, with healthy distal tissues. On day 8, the patient affirms having smoked, aggravating the viability of the skin overlying the middle phalanx, with consequent superficial necrosis on the dorsum of the middle phalanx of $2 / 1.5 \mathrm{~cm}$, managed through secondary healing with good results.
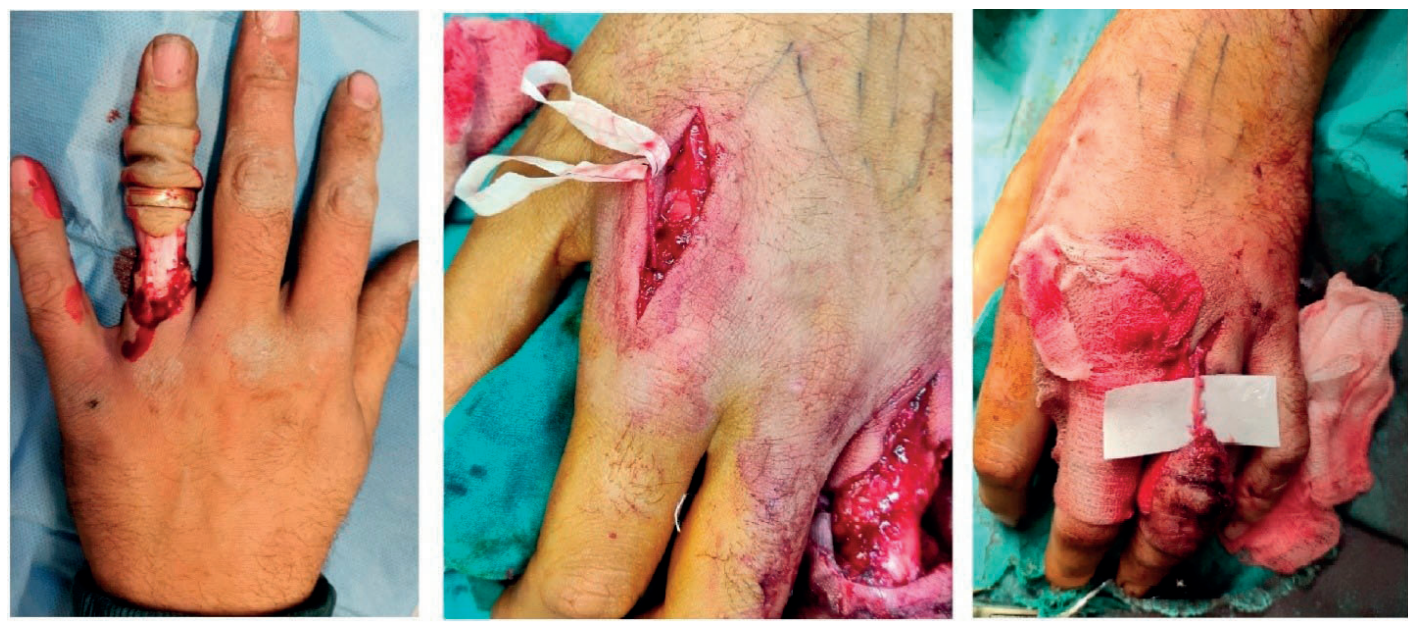

Figure 4. 26-year-old patient with finger ring avulsion injury mixed with crush injury of the middle phalanx skin. From left to right, the initial presentation of the degloving injury; vein graft harvesting from the dorsal area of the hand; interposed vein graft anastomosis

\section{DISCUSSIONS}

Upper limb trauma usually involves extensive tissular damage, which imposes aggressive debridement followed by the immediate and challenging decision to reconstruct through all means possible critical segments and restoring sensate function, whenever pos$\operatorname{sible}^{7,8}$. An experienced team in microsurgery with adequate prior training is required in order to undergo a successful procedure, using a special operating microscope. The most used donor site is the dorsum of the foot with good length, size match, with minimum donor site morbidity, hidden scar, ensuring an efficient repair ${ }^{9}$. Even though less applicable for veins with a small diameter, the interposed graft should be reversed as orientation in order to prevent early and mid-term higher chance of occlusion ${ }^{10}$.

In case of vascular or nervous defect, bone shortening, segment flexion, skeletonization of pedicle are usual the methods of choice, whenever healthy ends are found and the resulted gaps are under $1 \mathrm{~cm}$ for vessels $^{11,12,13}$. Direct coaptation can be achieved in case of gaps under $5 \mathrm{~mm}$ for nerves ${ }^{14,15}$. In cases of revascularization, where the bone structure may be intact with a large defect, or gaps resulting from debridement, interposition vein grafting represents a feasible choice for the vascular structures, applicable for trauma with nerve defects as well. However, the forearm and the dorsum of the hand both represent reliable sources, within the same surgical field ${ }^{10,13,14}$.

Severe upper limb trauma usually occurs in the category of labor active population; therefore, amputation should not be considered, even in heavily damaged cases. A mutilated hand with digit loss determines severe functional impairment, difficult to reconstruct or compensate by prosthetic devices. Advanced upper limb prostheses are not available to a wide range of patients due to financial aspect, while standard prostheses do not provide satisfactory results for a large number of 
patients. In addition, a prosthetic device lacks sensate function, an essential element of the hand ${ }^{16,17}$.

When looking at the patient distribution by age, we noticed that trauma patients represent almost three quarters of labor active population, implicitly with high social and economic impact due to such high percentages of debilitating injuries in the young population ${ }^{18}$. In addition, the aesthetic aspect of the hand in not only female, recently in male patients as well (affecting young people), is very important. Trauma in the hand renders not only major functional debilitating deficits in the hand, but also dramatically impacts the psychological outcome ${ }^{19}$.

All of the presented patients are young and part of the labor active population. For each presented case, the traumatic event posed significant functional and psychological concern, all of them pleading for segment preservation and displaying adherence to rehabilitations protocols.

Case 1: When attempting peripheral nerve reconstruction, the golden standard still standing to date is repairing the damaged nerve, whenever possible, end-to-end from healthy area to healthy area, preferably outside of injury zone, in a tension-free manner. Should the criteria not be met, autografts are the desired option. However, in cases where the defect is between $5 \mathrm{~mm}$ and 3 centimeters and donor site morbidity is not warranted, such as in sural nerve harvest or cutaneous nerves of the forearm harvest, an interposed conduit vein graft, harvested locally, preferably with muscle, may be the best choice acting as autologous non-immunologic conducts. Alternative methods are represented by biological and synthetic conduits ${ }^{13,15,20}$.

The patient presented criteria for muscle in vein graft since a low caliber distal nerve was affected, the radial collateral digital nerve, with a gap higher than 5 $\mathrm{mm}$ and the patient expressed desire for minimal donor site morbidity. The main disadvantage of choosing the vein conduit over nerve graft is lack of crucial elements that promote nerve regeneration such as laminin scaffolding and Schwan cells ${ }^{21}$.

The vein was filled with muscle in order to avoid venous collapse. In addition, $5 \mathrm{~mm}$ of the nerve ends were inserted into the vein in order to reduce the risk of end migration outside the conduit, according to literature recommendations ${ }^{13,21,22}$.

Case 2: The advantages of using a vein graft are bridging the gap without overcompensation using joint flexion or extension, a tension-free repair, outside of injury zone repair, also minimizing donor site morbidity, overall offering a viable back-up option, in the same surgical field, whenever aggressive debridement is performed. The disadvantages of using such technique are having two zones where anastomosis is performed, with a higher thrombogenic risk, a possible diameter mismatch, and initial difference in histological properties of the interposed vein to the arterial histology ${ }^{23}$.

In this case, a vein graft was harvested from an atypical area, the volar surface of the wrist, while dissecting the flexor pollicislongus proximal end, in order to minimize donor site morbidity as much as possible. The vein was mismatched in caliber compared to the distal stump of the ulnar digital artery in a ratio of 2:1. Anastomosis was performed using the wedge diameter reduction technique of the distal end of the vein. The follow-up was uneventful, and the patient started rehabilitation therapy.

Another reconstructive alternative is the arterialized venous flow-through-flap, where a skin island is harvested en bloc with the vein, providing soft-tissue coverage as well, if necessary ${ }^{24}$. Flexor pollicis longus hypoplasia and inability to flex the interphalangeal joint has been described with or without thumb hypoplasia. Patients with malformations may present a wide range of anatomical variances of the structures, posing a higher surgical complexity ${ }^{25}$.

Cases 3 and 4 were both caused through a ring avulsion mechanism. Degloving injuries in digits usually involve skin avulsion, with exposure of underlying structures. Urbaniak et al classified these injuries based on remaining vascularization and established the treatment option for each type as seen in Table $1^{26,27}$. Both latter cases meet the criteria of class II Urbaniak injury. Due to the friability of initially damaged vein ends, debridement resulting in a gap is frequent. Microsurgical venous reconstruction with interposed vein grafts presents the advantage of having identical histological structures, bridging of the injured area, however with thrombogenic risk due to two levels of anastomosis ${ }^{24,28}$.

Table 1. Urbaniak classification of ring avulsion injuries of the digits

\begin{tabular}{|l|l|l|}
\hline $\begin{array}{l}\text { Urbaniak } \\
\text { classification }\end{array}$ & Circulation & Treatment option \\
\hline Class I & Adequate & $\begin{array}{l}\text { Soft tissues and } \\
\text { bone reconstruction }\end{array}$ \\
\hline Class II & $\begin{array}{l}\text { Venous or arterial inadequate } \\
\text { circulation }\end{array}$ & Vessel repair \\
\hline Class III & $\begin{array}{l}\text { Complete amputation or both } \\
\text { venous and arterial inadequate } \\
\text { circulation }\end{array}$ & Amputation \\
\hline
\end{tabular}


Case 3 presented in addition to skin avulsion, unstable DIP joint dislocation, zone II complete extensor lesion, and section of the neurovascular pedicle on its radial side. After debridement, joint capsule reconstruction, extensor tendon repair and direct end-to-end direct repair of the sectioned nerve were performed. A venous gap resulted on the dorsal surface of the proximal phalanx, for which a direct repair was attempted. Due to the high tension of the venous anastomosis, usage of an interposed vein graft was decided. The result was reconstruction of a dorsal digital vein using an interposed vein graft, harvested from the dorsal surface of the hand. The patient underwent rehabilitation, with excellent recovery, re-established range of motion, with minimal loss of PIP and DIP flexion range.

Case 4, compared to the third case presented only one intact neurovascular pedicle, intact underlying structures. However, the skin on the proximal and middle phalanges suffered also a crushing type of injury underneath the ring. After initial debridement, a large venous gap resulted, for which a vein graft was harvested from the dorsum of the hand. Patient was not fully compliant regarding smoking ceasing, with subsequent superficial necrosis ${ }^{29}$.

\section{CONCLUSIONS}

Vein grafts are an asset for the microsurgeon when tackling simple to complex upper limb cases. They provide reliability and high adaptability to unique cases and in situations where a tension-free repair or a considerable arterial, vascular or nervous defects in the hand are met. Debridement to healthy area is imperative in upper limb trauma surgery. If a vessel gap of higher than $1 \mathrm{~cm}$ is met, an interposed vein graft or arterialized venous flow-through flap can be considered. The muscle in vein acts better than vein alone when repairing nerve graft, preventing vessel collapse, acting as an autologous conduit. Peripheral nerve defects can be bridged by interposed veins when the defect is larger than $5 \mathrm{~mm}$, but it should not exceed $3 \mathrm{~cm}$.

Compliance with ethics requirements: The authors declare no conflict of interest regarding this article. The authors declare that all the procedures and experiments of this study respect the ethical standards in the Helsinki Declaration of 1975, as revised in 2008(5), as well as the national law. Informed consent was obtained from all the patients included in the study. 


\section{References}

1. Brunelli GA, Battiston B, Vigasio A, Brunelli G, Marocolo D. Bridging nerve defects with combined skeletal muscle and vein conduits. Microsurgery. 1993;14(4):247-251. doi:10.1002/ micr.1920140407

2. HUGHES C. W. (1958). Arterial repair during the Korean war. Annals of surgery, 147(4), 555-561.

3. Heinzel JC, Quyen Nguyen $M$, Kefalianakis $L$, et al. A systematic review and meta-analysis of studies comparing musclein-vein conduits with autologous nerve grafts for nerve reconstruction. Sci Rep. 2021;11(1):11691. Published 2021 Jun 3. doi:10.1038/s41598-021-90956-3

4. Gardiner S, Friebel TR, Bray J, Anadkat M, Nikkhah D. Practical Techniques to Ensure Success in Digital Ring Avulsion Injuries. PlastReconstr Surg Glob Open. 2021;9(8):e3771. Published 2021 Aug 19. doi:10.1097/GOX.0000000000003771

5. Langer V. Management of major limb injuries. ScientificWorldJournal. 2014;2014:640430. Published 2014 Jan 5 doi:10.1155/2014/640430

6. Hamouya A, Barbato B, Beauthier-Landauer V, Hémon C. Complete ring finger avulsion: Review of 16 years of cases at a Hand Emergency Unit [published online ahead of print, 2018 May 25]. Hand Surg Rehabil. 2018;S2468-1229(18)30062-8. doi:10.1016/j.hansur.2018.03.003

7. Chang J, Neligan P. Volume 6: Hand and Upper, Reconstructive surgery of the mutilated hand. Amsterdam: Elsevier; 2018.

8. Wolfe, Scott W.;Pederson, William C.;Kozin, Scott H.;Cohen, Mark S.;Cohen, Mark S.Green's Operative Hand Surgery E-Book, 2016, Chapter 43, ISBN:9781455774272

9. Wenzel C, Brix E, Heidekrueger P, et al. The favorable donor site in microsurgery: Nerve and vein graft harvest from the dorsum of the foot [published online ahead of print, 2021 Oct 27]. Clin HemorheolMicrocirc. 2021;10.3233/CH-211135. doi:10.3233/ $\mathrm{CH}-211135$

10. Schanzer A, Hevelone N, Owens CD, et al. Technical factors affecting autogenous vein graft failure: observations from a large multicenter trial. J Vasc Surg. 2007;46(6):1180-1190. doi:10.1016/j. jvs.2007.08.033

11. Lee ZH, Klifto CS, Milone MT, et al. Survival after Digit Replantation and Revascularization Is Not Affected by the Use of Interpositional Grafts during Arterial Repair. PlastReconstr Surg. 2019;143(3):551e-557e. doi:10.1097/ PRS.0000000000005343q

12. Shaterian A, Sayadi LR, Anderson A, et al. Etiology and Survival of Secondary Revascularizations after Hand and Digit Replantations. J Hand Microsurg. 2020;12(2):111-115. doi:10.1055/s0039-3400442Boyd, K. U., \& Fox, I. K.. Nerve repair and grafting. Nerve repair. New York, NY: Thieme Medical Publishers, Inc, 2015, 75-100 ISBN: 9781588905130

13. Beris A, Gkiatas I, Gelalis I, Papadopoulos D, Kostas-Agnantis I. Current concepts in peripheral nerve surgery. Eur $\mathrm{J}$ Orthop Surg Traumatol. 2019;29(2):263-269. doi:10.1007/s00590-018-2344-2

14. Rebowe R, Rogers A, Yang $X$, Kundu SC, Smith TL, Li Z. Nerve Repair with Nerve Conduits: Problems, Solutions, and Future Directions. J Hand Microsurg. 2018;10(2):61-65. doi:10.1055/s-0038-1626687

15. BassiliosHabre $\mathrm{S}$, Bond G, Jing XL, Kostopoulos E, Wallace RD, Konofaos P. The Surgical Management of Nerve Gaps: Present and Future. Ann Plast Surg. 2018;80(3):252-261. doi:10.1097/ SAP.0000000000001252

16. Ribak S, de Oliveira EJN, Rosolino GP, Orru P, Tietzmann A. EPIDEMIOLOGY OF TRAUMATIC INJURIES OF THE UPPER LIMBS IN A UNIVERSITY HOSPITAL. Acta Ortop Bras. 2018;26(6):370-373. doi:10.1590/1413-785220182606180607
17. SensingerJW, Dosen S. A Review of Sensory Feedback in Upper-Limb Prostheses From the Perspective of Human Motor Control. Front Neurosci. 2020;14:345. Published 2020 Jun 23. doi:10.3389/fnins.2020.00345

18. BergmeisterKD, Große-Hartlage L, Daeschler SC, et al. Acute and long-term costs of 268 peripheral nerve injuries in the upper extremity. PLoS One. 2020;15(4):e0229530. Published 2020 Apr 6. doi:10.1371/journal.pone.0229530

19. Roberts JM, CarrLW, Haley CT, Hauck RM, Michelotti BF. Venous Flaps for Revascularization and Soft-Tissue Coverage in Traumatic Hand Injuries: A Systematic Review of the Literature. J ReconstrMicrosurg. 2020;36(2):104-109. doi:10.1055/s-0039-1695053

20. Bellaire $\mathrm{CP}$, Inglesby DC, Marayati NF, Warburton AJ, Melamed E. Trends in Peripheral Nerve Epidemiology and Reconstruction: A State Database Study of Direct Repairs, Grafts, and Conduits. Ann Plast Surg. 2021;87(2):179-186. doi:10.1097/ SAP.0000000000002823

21. Heinzel JC, Quyen Nguyen M, Kefalianakis L, et al. A systematic review and meta-analysis of studies comparing musclein-vein conduits with autologous nerve grafts for nerve reconstruction. Sci Rep. 2021;11(1):11691. Published 2021 Jun 3. doi:10.1038/s41598-021-90956-3

22. Riccio M, Marchesini A, Pugliese P, De Francesco F. Nerve repair and regeneration: Biological tubulization limits and future perspectives. J Cell Physiol. 2019;234(4):3362-3375. doi:10.1002/ jcp.27299

23. Lee, H. L., Shahriman, A. B., Za'aba, S. K., Khairunizam, W. A. N., Roohi, S. A., \&Zuradzman, M. R.. Upper extremity vein graft monitoring device after surgery procedure: a preliminary study. In Advanced Materials Research, Trans Tech Publications Ltd; 2014; Vol. 925, pp. 656-660).

24. Roberts JM, CarrLW, Haley CT, Hauck RM, Michelotti BF. Venous Flaps for Revascularization and Soft-Tissue Coverage in Traumatic Hand Injuries: A Systematic Review of the Literature. J ReconstrMicrosurg. 2020;36(2):104-109. doi:10.1055/s-0039-1695053

25. Dheer S, Ohb JS, Rivlin M. Flexor pollicis longus (FPL) tendon hypoplasia: A case report and literature review. Radiology Case Reports. 2019;14(5): 565-567

26. Urbaniak JR, Evans JP, Bright DS. Microvascular management of ring avulsion injuries. J Hand Surg Am. 1981;6(1):25-30. doi:10.1016/s0363-5023(81)80006-8

27. BonastreJuliá J, Ojeda Regidor Á, Martínez-Méndez J, et al. Clinical Outcomes in Ring Avulsion Fingers and Systematic Review of the Literature. Ann Plast Surg. 2020;85(6):631-637. doi:10.1097/ SAP.0000000000002453

28. Milone MT, Klifto CS, Lee ZH, Thanik V, Hacquebord JH. Relationships Between Vein Repairs, Postoperative Transfusions, and Survival in Single Digit Replantation. Hand (N Y). 2020;15(4):488494. doi:10.1177/1558944719828002

29. Gürbüz K, Yontar Y. A four-year community hospital experience regarding procedures for the replantation and revascularization of fingers. Jt Dis Relat Surg. 2021;32(2):383-390. doi:10.52312/ jdrs.2021.32 